\title{
Manuais para comunicadores: do local ao global, contribuições da mídia na redução de riscos de desastres
}

\author{
Clovis Reis ${ }^{1}$ \\ Regina Hostin ${ }^{2}$ \\ Yanet Reimondo Barrios ${ }^{3}$
}

\begin{abstract}
Resumo
A mídia cumpre um papel fundamental em todas as fases de um desastre, e essa relação entre os dois temas resultou na produção de manuais dirigidos aos profissionais que formam a opinião pública e fazem a cobertura do assunto. $O$ objetivo deste trabalho é analisar alguns desses manuais que trazem orientações sobre os riscos de desastres e refletir sobre a contribuição da mídia no aplacamento dos impactos desses desastres. A pesquisa concentrou-se na identificação de manuais para comunicadores que fazem a cobertura dos riscos de desastres, na descrição do conteúdo e, por fim, na reflexão sobre o papel da mídia na cobertura de tais eventos. Em relação à metodologia, optou-se pela análise do conteúdo dos cinco manuais selecionados. Concluiu-se que o tema é tratado de forma abrangente e atribui aos comunicadores a tarefa de impulsionar mudanças profundas em toda a sociedade, as quais perpassam pela educação e conscientização.
\end{abstract}

Palavras-chave: Mídia. Manual para Comunicadores. Desastre. Defesa Civil. Gestão de Risco de Desastres.

\begin{abstract}
The media play a key role in all phases of a disaster, and this relationship between the two themes has resulted in the production of manuals for professionals who form public opinion and cover the subject. The objective of this work is to analyze some of these manuals that provide guidelines on disaster risks and to reflect on the contribution of the media in mitigating the impacts of these disasters. The research focused on the identification of manuals for communicators covering disaster risk, describing the content and, finally, reflecting on the role of the media in covering such events. Regarding the methodology, we opted for the analysis of the contents of the five selected manuals. It was concluded that the topic is treated comprehensively and assigns to the communicators the task of promoting profound changes throughout society, which go through education and awareness.
\end{abstract}

Keywords: Media. Manual for Communicators. Disaster. Civil defense. Disaster Risk Management.

\section{Introdução}

Nas últimas décadas, o estudo dos desastres ambientais ganhou destaque na pesquisa acadêmica, adotando diferentes perspectivas de investigação e dando origem a

\footnotetext{
${ }^{1}$ Doutor em Comunicação. Professor do Programa de Pós-Graduação em Desenvolvimento Regional da Universidade Regional de Blumenau (FURB ).professorclovisreis@gmail.com

${ }^{2}$ Mestre em Desenvolvimento Regional. FURB. regina.compartilha@gmail.com

${ }^{3}$ Doutoranda do Programa de Pós-Graduação em Desenvolvimento Regional da Universidade Regional de Blumenau (FURB). yanet.barrios89@gmail.com
} 
uma série de métodos para a avaliação de múltiplos aspectos da tragédia (HUANG, LIU e MA, 2011). Relatórios da ONU, divulgados pelos jornais Folha de São Paulo, O Estado de S. Paulo e O Globo, revelaram que, em 2008, 117 milhões de pessoas em todo o mundo foram atingidas por cerca de 300 desastres naturais, incluindo secas devastadoras, na China e na África, e inundações na Ásia e na África, resultando um prejuízo total de US\$ 15 bilhões. Só em 2007, um total de 197 milhões de pessoas foram vítimas de desastres, sendo 164 milhões vitimadas por inundações (ZUCCO; MAGALHÃES; MORETTI, 2010).

O conceito de desastres leva a inúmeras discussões, e, em boa parte delas, está em xeque a relação do homem com a natureza. "Para os jornalistas, um desastre é o tipo de notícia de última hora que merece ampla cobertura" (POTTER; RICCHIARDI, 2009, p. 8). Segundo Avila e Mattedi (2015), os desastres “[...] decorrem da construção social do risco e [...] resultam da interação entre ameaças naturais e sociais, condições de vulnerabilidade e insuficiente capacidade para reduzir as consequências negativas do risco na sociedade" (AVILA; MATTEDI, 2015, p. 3). De forma mais específica, em termos sociológicos, "[...] sua utilização reporta-se, especificamente, a um acontecimento, ou uma série de acontecimentos, que alteram o modo de funcionamento rotineiro de uma sociedade" (MATTEDI; BUTZKE, 2001, p. 9).

A participação da mídia na cobertura de desastres existe desde o início da imprensa (ZENATTI; SOUSA, 2010, p. 10). A relevância do trabalho da mídia em todas as fases de um desastre resultou na produção de manuais dirigidos aos profissionais que formam a opinião pública e fazem a cobertura do tema. Os guias contemplam tópicos diversos, como orientações para a cobertura jornalística de desastres, questões éticas, o bem-estar emocional dos jornalistas que cobrem essa área e a terminologia em desastres.

Nesse contexto, a pesquisa se concentra em identificar os materiais, descrever o conteúdo e, por fim, refletir sobre como a mídia pode contribuir para amenizar os impactos de um desastre. Foram encontrados nove manuais nos idiomas português, espanhol e inglês, e escolhidos aqueles de organismos representativos e com ampla circulação. A escolha dos manuais também privilegiou diferentes localidades, sendo contemplados dois manuais internacionais, um latino-americano, um nacional e um local.

O presente estudo soma-se aos esforços do grupo de pesquisa Estudos Midiáticos Regionais, voltado à compreensão do papel da mídia durante os desastres (REIS; ZUCCO, 2012; REIS; ZUCCO; DAROLT, 2013; REIS; CARDOSO, 2014; CARDOSO; DAROLT; REIS, 2015; REIS; MATTEDI; REIMONDO BARRIOS, 2017, entre outros). Para abordar essas preocupações, 
o trabalho objetiva analisar os manuais que orientam a mídia na comunicação de riscos de desastres. O campo é vasto, e dele emergem muitos questionamentos: Quais informações os manuais contêm? Quais são as orientações para a atuação da mídia em relação a desastres? Como a mídia pode contribuir para amenizar os impactos de um desastre?

\section{Mídia e desastres}

Tendo a capacidade de alterar o cotidiano de uma comunidade, o desastre pode ser encarado como um problema social. A relevância do tema tem apontado diferentes perspectivas de estudos. Uma delas, foco deste artigo, constitui-se na relação entre os riscos de desastres e o papel da mídia, o qual se mostra como um campo primordial, já que os desastres "[...] afetam diretamente o diálogo e a interação do poder público com a população" (REIS, ZUCCO e DAROLT et al, 2013, p 157). A comunicação entre poder público e comunidade atingida, antes, durante e depois de um desastre, está diretamente relacionada à forma de gerir a crise. A informação - ou a falta dela - pode influenciar de maneira positiva ou negativa todas as fases do desastre. Nesse sentido,

[...] os meios de comunicação prestam relevantes serviços para a sociedade, uma vez que configuram os canais privilegiados para que os gestores da crise se comuniquem com o público em ocasiões de perigo iminente. $O$ alcance dos jornais, da televisão, do rádio e das mídias sociais permite que as mensagens cheguem com a frequência e o conteúdo necessários até as pessoas que, de outro modo, se encontrariam isoladas durante uma situação de emergência (REIS; ZUCCO; DAROLT, 2013, p. 158).

De acordo com Barrios, Arroyave Cabrera e Veja-Estarita (2017), em se tratando de ética, o bom jornalismo deve fornecer as informações necessárias para que as pessoas tomem decisões. No cenário da gestão de riscos de desastres, as informações são ainda mais importantes para as comunidades, pois delas depende uma melhor qualidade de vida, devido ao conhecimento dos riscos a que estão expostas. Dessa forma, existe a chance de redução desses riscos e mesmo a prevenção de potenciais perdas de vidas e danos materiais derivados de uma emergência (BARRIOS; ARROYAVE CABRERA; VEGA-ESTARITA, 2017).

Na mesma direção, Spence, Lachlan e Griffin (2007) afirmam que a comunicação em tempos de crise busca prevenir ou diminuir os resultados negativos de um episódio. Para os autores, a comunicação cumpre, sobretudo, duas funções. Primeiro, a informativa, quando 
as mensagens devem criar uma compreensão racional do risco. Depois, persuasiva, na medida em que deve incentivar o público a adotar precauções para atenuar suas consequências. Radford e Wisner (2012) afirmam que, para convencer as pessoas, você tem que persuadir e, em seguida, continuar a persuadir. Para os autores, o que a mídia poderia e deveria fazer é contar a mesma história e reforçar a mesma mensagem no maior número possível de vezes e maneiras diferentes.

Nas últimas décadas, a comunicação de desastres tem sido pauta nos debates internacionais. Um dos primeiros encontros sobre o tema ocorreu em 1990, promovido pela ONU. Após 25 anos, o reconhecimento de que a gestão de risco de desastres envolve atividades intensivas de informação e comunicação deu origem a conferências internacionais sobre tecnologias da informação e comunicação na gestão de desastres, realizadas em 2014, 2015 e 2016. A pesquisa sobre mídia e desastres tem experimentado também uma expansão e um aprofundamento contínuos. Temas como o uso das novas tecnologias na mitigação de desastres (HANS; MOHANTY, 2006) e a aplicação de sistemas de mídia social para a gestão moderna de emergência (BRUNS; LIANG, 2012; CROWE, 2012) ganham destaque na pesquisa científica.

No entanto, uma pesquisa sobre as tendências e padrões de mídia e desastres nos últimos 20 anos (REIS; MATTEDI; BARRIOS; 2017) revelou a pouca atenção aos desastres antes que eles ocorressem, apesar do reconhecimento do importante papel da mídia na prevenção e redução de seus riscos. Ignoram-se as questões de longo prazo, e a maior parte da cobertura ocorre ainda na própria catástrofe (REIS; MATTEDI; BARRIOS; 2017). Os casos analisados mostraram que, em situações de desastre, tanto o trabalho das autoridades e instituições do governo como a relação entre jornalistas e gestores de emergência precisam acontecer de outra forma. Por um lado, existem decisões políticas e administrativas que devem ser tomadas antes de qualquer catástrofe, impactando a capacidade coletiva de responder eficazmente aos desastres. Por outro, é fundamental ter os meios de comunicação como aliados na preparação e participação da sociedade de forma preventiva (REIS; MATTEDI; BARRIOS, 2017).

O trabalho dos jornalistas não é focado na prevenção. Em geral, quando ocorrem os desastres, a atenção dos comunicadores concentra-se nas emergências e perdas humanas e econômicas (BARRIOS; ARROYAVE; VEGA-ESTARITA, 2017). De acordo com Radford e Wisner (2012), o desafio é incluir esses temas nas páginas de notícias antes que a morte e o 
sofrimento aconteçam. Isso requer conexão entre a comunidade profissional de desastres e a mídia.

\section{Metodologia}

A pesquisa concentrou-se na identificação de manuais para comunicadores sobre a cobertura de riscos de desastres, na descrição do conteúdo e, por fim, na reflexão sobre como a mídia pode contribuir para amenizar os impactos de um desastre. Através de buscas em websites de pesquisa na Internet e utilizando as expressões "manual para comunicadores", "mídia e desastre", "defesa civil" e "gestão de risco de desastres", foram encontrados nove manuais nos três idiomas pesquisados (português, espanhol e inglês). Os critérios de escolha foram os da representatividade e ampla circulação desses organismos. Também se optou por diversificar sua origem e abrangência. Dessa forma, contemplaram-se dois manuais internacionais, um latino-americano, um nacional e um local.

Após a escolha dos manuais, foi realizada uma análise de conteúdo de todo o material, cuja metodologia vem se desenvolvendo desde o início do século XX no mundo acadêmico, essencialmente no âmbito das Ciências Sociais Aplicadas. No campo de pesquisa científica em comunicação de massa, tem sido o método de maior crescimento nos últimos 20 anos (NEUENDORF, 2002, p.1). Segundo Bardin (2010), com a análise de conteúdo, o pesquisador busca compreender o sentido da comunicação, tentando encontrar outra significação implícita.

Foram estipuladas três fases na análise. Na primeira, classificada como pré-análise, foram estabelecidos o esquema de trabalho e os questionamentos que orientaram a interpretação do material. Nesse caso, serviram como guia as três perguntas: Quais informações os manuais contêm? Quais são as orientações para atuação da mídia em relação a desastres? Como a mídia pode contribuir para amenizar os impactos de um desastre?

A segunda fase compreendeu a leitura do material, o fichamento, categorização e a busca de conteúdo que respondesse aos questionamentos que norteiam a pesquisa. A última fase teve como objetivo interpretar e refletir sobre os resultados em busca de padrões ou relações. 


\section{Resultados}

Neste tópico, serão identificados os manuais e descritos os seus respectivos conteúdos. Foram contemplados dois materiais internacionais, um latino-americano, um nacional e um local. São eles: O desastre sob o enfoque de novas lentes: para cada efeito uma causa, produzido pela UNISDR (Nações Unidas - Estratégia Internacional para Redução de Desastres - Nações Unidas), em 2012; Cobertura de Desastres e Crises, editado pelas jornalistas americanas Deborah Potter e Sherry Ricchiardi, do Centro Internacional para Jornalistas (ICFJ - International Center for Journalists), em 2009; Manual de Gestão de Riscos de Desastres para Comunicadores Sociais - um guia prático para o comunicador social comprometido em informar e educar para salvar vidas, lançado pela UNESCO, em 2011; Comunicação em Desastres - A Atuação da Imprensa e o Papel da Assessoria Governamental, das jornalistas Ana Paula de Assis Zenatti e Soledad Yaconi Urrutia de Sousa e publicado pelo Governo do Estado de Santa Catarina, por meio do Departamento Estadual de Defesa Civil e do Centro Universitário de Estudos e Pesquisas sobre Desastres - CEPED UFSC, em 2010; e o Plano de Contingência - Inundações e Escorregamentos, de 2016, idealizado pela Defesa Civil de Blumenau (SC) em 1989, pela primeira vez, e atualizado anualmente.

Nesta etapa, entre outros assuntos, serão abordadas as informações que os manuais contêm e também as orientações para a atuação da mídia em relação a desastres.

\section{Manuais internacionais}

5.1 O manual "O desastre sob o enfoque de novas lentes - para cada efeito, uma causa" (2012)

O manual "O desastre sob o enfoque de novas lentes - para cada efeito, uma causa" (2012), da UNISDR (Nações Unidas - Estratégia Internacional para Redução de Desastres ${ }^{4}$ ), é um guia que orienta a cobertura jornalística em Redução de Riscos de Desastres (RRD). Foi

\footnotetext{
${ }^{4}$ A Estratégia Internacional para Redução de Desastres (ISDR, na sigla em inglês) é adotada pelos Estados Membros das Nações Unidas em 2000, que guia e coordena os esforços de uma ampla rede de parceiros para alcançar uma redução substancial das perdas ocasionadas por desastres e construir nações e comunidades resilientes como uma condição essencial para o desenvolvimento sustentável (UNISDR, 2012, p. 5).
} 
redigido por Brigitte Leoni, Chefe de Comunicações da UNISDR; Tim Radford, jornalista do The Guardian; e Mark Schulman, consultor da UNISDR. A tradução, em 2012, para o idioma português contou com o financiamento da Comissão Europeia, no âmbito do projeto "Aumentando Resiliências \& Fortalecendo Comunidades: RRD na prática no Brasil”, realizado pela CARE Brasil em parceria com a Fundação Abrinq/Save the Children. Está estruturado em cinco capítulos mais uma conclusão intitulada "O poder da mudança", tudo distribuído em 179 páginas. Tem o intuito de contribuir com jornalistas e profissionais de mídia interessados em aprender mais sobre a redução de riscos de desastres.

Um desastre pode atingir qualquer local, comunidade, construção. Um desastre pode chegar a qualquer momento. Sem aviso prévio. Sem que haja tempo para reação. E isso tem se tornado cada vez mais frequente. Os veículos de comunicação - jornais, rádio, televisão e todas as outras mídias da internet - podem fazer uma grande diferença para reduzir os riscos de desastres. É este o foco do Manual, que credita aos profissionais de comunicação a tarefa de ir além da simples informação. Há um reconhecimento de que os jornalistas podem fazer a diferença "[...] na forma como as pessoas pensam e agem, especialmente neste momento em que as mudanças climáticas são reconhecidas como um grande desafio que poderá agravar nossa vulnerabilidade aos desastres" (UNISDR, 2012, p. 12). O guia destaca a importância de os profissionais mostrarem as causas do desastre e suas dimensões sociais, para que as comunidades compreendam o que as torna vulneráveis e quais ações podem ampliar suas capacidades para lidar com os desastres. Atribui ao jornalismo o papel de uma ponte entre comunidades e governos, o que, de fato, pode contribuir para a mudança de uma cultura reativa para uma cultura de prevenção.

Todo o conteúdo do material é escrito de forma clara, permeado por fotos e gráficos, revelando que foi preparado por uma equipe especialista em desastres, cujos componentes “[...] entendem que a redução de riscos de desastres é um dever cívico, uma responsabilidade governamental, uma obrigação nacional e uma boa estória para virar notícia" (UNISDR, 2012, p. 13). Já na introdução, o Manual reforça a diferença entre ameaças naturais e desastres. Frisa que ameaças são naturais, mas os desastres não (UNISDR, 2012). Por isso, orienta que os jornalistas evitem o termo desastres naturais e usem desastre ou ameaças naturais.

Os autores abrem o primeiro capítulo, "O que você precisa saber sobre Redução de Riscos de Desastres", abordando a terminologia deste campo, revelando o significado de 
palavras como ameaça, desastre, risco, vulnerabilidade, entre outros. Em seguida, o capítulo mostra ainda estatísticas, o porquê de estarem ocorrendo tantos desastres, prevenção e responsabilidades. Fecha com perguntas e respostas sobre o tema, apontando uma lista com as dez questões mais frequentes sobre redução de riscos de desastres e ainda mensagenschave sobre o tema.

Do primeiro capítulo para o segundo, o Manual deixa de lado o básico e já entra em temas que relacionam diretamente mídia e desastres. Sob o título "A Redução de Riscos de Desastres e a Mídia", a segunda parte destaca que "[...] a mídia pode influenciar as decisões políticas, alterar atitudes públicas e, claro, salvar vidas" (UNISDR, 2012, p. 66), e isto passa por perguntas como as seguintes: Por que os desastres ocorrem? Como os desastres podem ser prevenidos? De quem é a responsabilidade? Nesta parte do Manual, está o principal conteúdo, pois traz informações sobre a responsabilidade da mídia na cobertura dos desastres e as boas razões para abordar a RRD.

\footnotetext{
No decorrer das últimas três décadas, meios de comunicação, editores de revistas, jornalistas e blogueiros têm ajudado a provocar mudanças sociais em atitudes relacionadas à bebida, cigarro, alimentação, HIV e AIDS, e meio ambiente. Se a Redução de Riscos de Desastres tornar-se parte da agenda nacional, civil e midiática, isto terá ocorrido em função da cobertura sistemática, medida e sensível feita por profissionais responsáveis e esclarecidos que fazem parte da mídia (UNISDR, 2012, p. 70).
}

Neste ponto, destaca a importância dos veículos de comunicação terem uma política interna que defina quem faz a cobertura; um plano de contingência para enfrentar situações de desastres e para repassar mensagens de alerta; a atribuição do trabalho a um repórter; tempo e espaço para as investigações sobre as causas de um desastre; investimento em conhecimento sobre RRD e programas educativos para sensibilizar e divulgar conhecimento aos públicos mais vulneráveis. Orienta especificamente os repórteres para que tenham uma agenda com as possíveis fontes especializadas em riscos urbanos, mudanças climáticas, meio ambiente e desenvolvimento; para que mantenham contatos pessoais com esses profissionais, antes de ocorrer um evento, bem como com os órgãos nacionais e locais de meteorologia e órgãos envolvidos na redução de risco e defesa civil; para que busquem familiaridade com as áreas mais propensas e vulneráveis a desastres e com as principais medidas de prevenção e mitigação adotadas pelas autoridades locais; para que mantenham um histórico sobre os principais desastres passados e lições aprendidas; para que tenham 
como base de informação apenas o conhecimento científico sólido; e, finalmente, visitem e ouçam as comunidades.

De forma geral, recomendam ainda que, antes dos desastres, os jornalistas investiguem o potencial das ameaças e dos riscos da sua região; não esperem que um desastre aconteça para escrever sobre as ameaças; pesquisem o que está sendo feito em RRD; mantenham viva a memória de desastres passados; cubram simulados; construam regularmente histórias com pessoas de áreas vulneráveis a desastres; organizem reuniões informais e regulares com o meio científico e acadêmico, o qual possua material útil sobre avaliação de risco e medidas de mitigação; aproveitem a ocorrência de um desastre internacional para enfatizar os riscos de uma área de risco local ou nacional. E, após os desastres, sugerem que sejam informadas as causas do evento, e não apenas os fatos; levantadas informações sobre os sistemas de alerta e alarme e sobre o planejamento urbano; atentem para a construção da resiliência, das ações dos responsáveis pela gestão do desastre, dos investimentos, dos recursos financeiros e políticas em RRD, dos impactos econômicos, sociais e culturais do desastre; que sejam encontrados especialistas que possam identificar lições e busquem informações sobre ocorrências semelhantes - ou desastres anteriores em outros países - para informar sobre possíveis soluções. Contempla ainda uma lista de afazeres composta por uma relação de perguntas que deveriam ser feitas (das mais gerais às mais específicas) e ainda dá exemplos de reportagens sobre RRD, as quais colocaram a lista dos afazeres em prática.

No capítulo 3, "Lições de RRD", a partir de quatro desastres, são abordados os eventos Tsunami do Oceano Índico (2004); Monte Pinatubo, Filipinas (1991); Furacão Katrina, Estados Unidos (2005); Terremoto da Caxemira, Paquistão (2005). Nesta parte, sustentam os especialistas que as lições dos eventos ocorridos podem funcionar como um roteiro para uma matéria sobre desastres.

O penúltimo capítulo, "Informações úteis sobre ameaças naturais", reúne dados sobre avalanches, secas e estiagens, terremotos, inundações, furacões, ciclones e tufões, deslizamentos, tornados, tsunamis, vulcões, incêndios florestais. São números, descrições, fatores de risco, áreas vulneráveis, medidas de redução de riscos e links úteis. Na mesma linha, o quinto e último capítulo, "Fontes e Referências em Redução de Riscos de Desastres", concentra dados sobre fontes, que contribuem para formar ou atualizar o banco de dados dos profissionais da imprensa. Agrupa informações sobre centros de informação, 
publicações sobre RRD, especialistas (lista de organizações internacionais que trabalham com o tema de Redução de Riscos de Desastres) e, por fim, lista de contatos de atendimento à imprensa e meios de comunicação em geral, entre os quais as principais organizações internacionais e das Nações Unidas que trabalham com o tema da Redução de Riscos de Desastres.

Ao final, o Manual é finalizado com três anexos. O primeiro, "Uma breve história sobre a evolução da Redução de Riscos de Desastres", é baseado numa entrevista dada por Andrew Maskrey, Assessor Sênior da UNISDR, encarregado da coordenação do Relatório de Avaliação Global em RRD (Global Assessment Report on Disaster Risk Reduction). O anexo dois, "Terminologias", contempla o significado de termos como aquecimento global, desastre múltiplo, desenvolvimento sustentável, mudanças climáticas, risco aceitável e outros. O anexo três, "A corrupção custa vidas", baseia-se em uma entrevista com James Lewis, escritor da área de arquitetura e meio ambiente e membro do Royal Institute of British Architects (RIBA) com Datum International.

\subsection{Bem-estar em foco}

O segundo manual internacional é intitulado "Cobertura de Desastres e Crises". Foi editado pelas jornalistas americanas Deborah Potter e Sherry Ricchiardi, do Centro Internacional para Jornalistas (ICFJ - International Center for Journalists ${ }^{5}$ ), com o apoio da Fundação McCormick, em $2009^{6}$. Em relação às autoras, Deborah Potter é diretora executiva do NewsLab, uma organização sem fins lucrativos que fornece recursos jornalísticos, com sede em Washington, DC. Sherry Ricchiardi, Ph.D., é escritora executiva da American Journalism Review, revista especializada em questões internacionais.

O manual está disponível na internet nas versões em inglês e em espanhol. Tem 64 páginas e foi dividido em duas partes. A primeira tem nove subtítulos e fornece informações sobre questões operacionais que envolvem a distribuição de notícias. A introdução é seguida do tópico "Preparação da Sala de Redação", onde são fornecidas informações sobre como

\footnotetext{
${ }^{5}$ O Centro Internacional para Jornalistas é uma organização profissional sem fins lucrativos, que acredita que os meios independentes são cruciais para melhorar a condição humana. Desde 1984, trabalha diretamente com mais de 55 mil jornalistas de 176 países (POTTER; RICCHIARDI, 2009).

${ }^{6}$ Fundação McCormick, uma organização sem fins lucrativos, comprometida em fortalecer uma sociedade livre e democrática, através do investimento nas crianças, nas comunidades e no país (POTTER; RICCHIARDI, 2009).
} 
contatar os profissionais e as responsabilidades específicas de cada um da equipe. 0 subtítulo seguinte trata de como desenvolver um plano para enfrentar um desastre e fornece um cuidadoso passo a passo para os profissionais da redação estarem preparados. A primeira parte faz referência ainda à importância de prever os desastres exercitando a pergunta: Quais são os desastres mais prováveis que estaremos enfrentando em breve? Vulcões, acidentes, maremotos? Aborda também como fazer a cobertura, um plano para manter a sala de redação em funcionamento, no caso de ser atingida pelo desastre, os recursos da internet, a preparação pessoal do jornalista e os materiais para o trabalho fontes, perguntas, checagem de dados, agenda, etc., e, por fim, discorre sobre a segurança do jornalista.

A segunda parte divide-se em como os jornalistas interagem com as vítimas, sobreviventes e testemunhos de uma tragédia, e como reagem ao impacto emocional do trauma. Apresenta conceitos sobre estresse traumático, seus sinais e a natureza do trauma. Segue com sugestões sobre como lidar com vítimas e sobreviventes, forma de abordagem, perguntas, respeito, o que não fazer. Este tópico conduz os leitores a uma reflexão sobre dizer a verdade e minimizar os danos às pessoas vulneráveis. Esta segunda parte trata também do trabalho dos fotógrafos e profissionais que atuam como câmeras e o que devem considerar para evitar serem vistos como intrusos e minimizar danos. E ainda versa sobre apoio e coaching aos jornalistas que cobrem eventos catastróficos, revelando uma preocupação com o bem-estar emocional desses profissionais. De forma breve, mas cautelosa, termina com conselhos para que o jornalista cuide de si mesmo, perceba seus limites, não menospreze as experiências vividas e não sabote as emoções.

\section{Manual latino-americano: apoio educativo e informacional}

O “Manual de Gestão de Riscos de Desastres para Comunicadores Sociais - um guia prático para o comunicador social comprometido em informar e educar para salvar vidas" foi lançado em 2011 pela Organização das Nações Unidas para a Educação, a Ciência e a Cultura - Representação Peru. Está publicado em espanhol e assinado pelo consultor Fernando Ulloa. Tem 69 páginas divididas em nove capítulos mais um glossário ao final.

O objetivo do material é sensibilizar e apoiar o comunicador e jornalista em seu trabalho de informar e educara população, com foco na gestão de risco de desastres. 0 
manual pretende ainda que o tema se torne parte da agenda de notícias dos meios de comunicação para prevenir que os riscos se convertam em desastres. Além disso, procura também orientar o uso da terminologia técnica correta e das metodologias adequadas para a gestão da informação.

O primeiro capítulo foca no meio ambiente e na gestão de riscos de desastres, contemplando a etimologia e a visão de mundo dos desastres, o território, o risco de desastre, a categorização de eventos (crise, emergência, desastre e catástrofe, gestão do risco de desastres). O segundo capítulo já une a comunicação, a informação e a redução de desastres. Nessa parte, posiciona o comunicador como o elo entre a população e os órgãos científicos e as instituições públicas e privadas, responsáveis pela gestão do risco de desastres (UNESCO, 2011). Trata ainda dos seguintes assuntos: o público e a percepção de risco, o processo de comunicação na gestão de riscos de desastre, as ações de comunicação para a gestão de risco de desastre, a comunicação nos três tipos de gestão (corretiva, prospectiva e reativa), para a redução de risco, e a cultura de prevenção na população.

Já nos capítulos 3 e 4, estão concentradas as estratégias de comunicação e os processos de comunicação para a gestão de risco de desastres. Dentre as orientações aos jornalistas, destacam que os períodos de normalidade são os momentos ideais para a educação da população na gestão do risco de desastres, pois é quando essa população está mais receptível às informações. Reforçam ainda que, durante uma crise, uma emergência, um desastre ou uma catástrofe, a rapidez na transmissão de informações é fundamental e que a circulação oportuna e transparente ajuda a gerar confiança e credibilidade. Tratam também da importância de reconhecer o evento com empatia, informar e explicar a situação tecnicamente, mas da maneira mais simples possível, para que as mensagens possam ser entendidas por todos.

No capítulo seguinte, a ética ganha destaque. O tema é levantado sob várias perspectivas: os aspectos éticos da comunicação em situações de emergência, a ética da informação e da comunicação social, os princípios internacionais da UNESCO sobre a ética profissional do jornalista, os códigos de ética e de conduta.

Nos capítulos 6, 7 e 8, o guia faz referência às organizações relacionadas com a gestão do risco de desastres no Peru, saúde mental e recuperação socio emocional do comunicador, e abordagem correta em situações de emergência, respectivamente. Percebese novamente a preocupação com o bem-estar psicológico do jornalista responsável pela 
cobertura de desastres. O material termina tratando das novas tecnologias nos processos de informação e comunicação social para a gestão do risco de desastre.

7 Nacional: mídia e assessoria de imprensa

O livro "Comunicação em Desastres - A Atuação da Imprensa e o Papel da Assessoria Governamental" trata do tema comunicação e desastres sob outra perspectiva. Foi publicado pelo Governo do Estado de Santa Catarina, por meio do Departamento Estadual de Defesa Civil e do Centro Universitário de Estudos e Pesquisas sobre Desastres - CEPED UFSC (Centro Universitário de Estudos e Pesquisas sobre Desastres/Universidade Federal de Santa Catarina). Contou com o apoio da Associação Catarinense de Imprensa. A obra tem 120 páginas e foi lançada em 2010, somente na versão em português. Tem como autoras as jornalistas Ana Paula de Assis Zenatti e Soledad Yaconi Urrutia de Sousa. Ana Paula de Assis Zenatti é Executiva de Conta na Edelman Brasil de Relações Públicas. Soledad Yaconi Urrutia de Sousa foi Assessora de Comunicação do Departamento Estadual de Defesa Civil e responsável pela coordenação dos trabalhos na base da Central de Comunicação, montada em Florianópolis, durante o desastre de 2008.

A obra está dividida em quatro capítulos e reuniu conceitos e ações práticas de comunicação para mostrar a necessidade de maior integração entre mídia e assessoria de imprensa governamental (ZENATTI; SOUSA, 2010). O primeiro capítulo reconta de forma breve a história da imprensa no mundo e, depois, revela números dos desastres de forma geral, bem como a relação do tema com a mídia no decorrer dos anos. Aproxima os assuntos da realidade catarinense e destaca que "[...] o furacão Catarina é considerado a primeira grande experiência em Santa Catarina com a participação da mídia nas etapas pré desastre de atuação da Defesa Civil [...]" (ZENATTI; SOUSA, 2010, p. 10). Em seguida, o capítulo traz um breve histórico do início da comunicação humana, bem como a história da imprensa no Brasil; por fim, a atuação da imprensa em desastres.

Hoje, o grande desafio é ter os meios de comunicação como aliados no repasse das informações sobre desastres antes mesmo de eles acontecerem, resultando na minimização dos riscos e garantindo a participação da sociedade de forma preventiva" (ZENATTI; SOUSA, 2010, p. 17). 
O capítulo dois aborda o papel da imprensa na divulgação e informação de desastres, contemplando as características de cada meio de comunicação. No terceiro capítulo, as autoras falam do conceito de assessoria de imprensa (Al) e o seu trabalho no processo de divulgação de informações em situações de desastres. Tratam também sobre comunicação preventiva e como o Sistema Nacional de Defesa Civil divide o gerenciamento de desastres, versando ainda sobre o plano de comunicação para desastres, a formalização estratégica das ações que a assessoria de imprensa desenvolverá numa determinada organização (antes, durante e depois) e quais as ferramentas que serão utilizadas para divulgar as informações.

O último capítulo foca num exemplo prático de gerenciamento da comunicação governamental, em uma situação de desastre, a partir da tragédia de 2008, em Santa Catarina. Relatam as autoras as ações ocorridas antes, durante e depois do episódio. Ao final, apresentam um Plano de Comunicação da Defesa Civil de Santa Catarina e um Glossário de Defesa Civil.

No mesmo ano do lançamento do livro, foi criado o curso "Comunicação de Riscos e de Desastres" para jornalistas, comunicadores, estudantes de jornalismo, pesquisadores da área e profissionais da Defesa Civil. O curso é realizado a distância e promovido pela Secretaria Nacional de Defesa Civil em parceria com o CEPED UFSC.

\section{Local: Plano de Contingência}

O "Plano de Contingência - Inundações e Escorregamentos", de Blumenau (SC), tem o objetivo de organizar as ações dos órgãos públicos, privados e da comunidade frente a desastres, inundações e escorregamentos que ocorrem no município. Blumenau tem sua história marcada por inundações desde sua fundação em 1850. Mais recentemente, também por escorregamentos, o que gera danos e impactos em toda a comunidade.

O Plano de Contingência tem 422 páginas. Foi idealizado pela Defesa Civil, pela primeira vez, em 1989, sendo atualizado anualmente. Delimita medidas preventivas, de resposta, assistenciais e recuperativas. O plano também prevê diferentes etapas de execução, cada uma delas com atribuições aos setores envolvidos. Na primeira parte, é apresentada a organização das áreas de Defesa Civil, a descrição da estrutura do Grupo de Ações Coordenadas (GRAC), que conduz as atividades da Defesa Civil, e, também, apresentadas as fases do plano (Prevenção e Preparação, Resposta e Reconstrução) em 
relação à evolução do evento. O plano possui quatro anexos. O primeiro é denominado de Normas Gerais de Ação (NGA) e estabelece atribuições aos diversos integrantes do Grupo de Ações Coordenadas nas diversas fases do plano. O segundo anexo trata dos sessenta abrigos quanto a sua estrutura, equipe de coordenação e aspectos logísticos. O terceiro concentra o levantamento logístico nas cinco áreas de Defesa Civil, e o último anexo relaciona entidades e pessoas integrantes do GRAC e demais órgãos de relacionamento da Defesa Civil de Blumenau, com telefones de contato.

Não há, no manual, orientações para a atuação da mídia durante desastres. A única menção que lhe é feita acontece no primeiro anexo, quando são tratadas as atribuições da Secretaria Municipal de Comunicação Social (SECOM) da Prefeitura, uma das integrantes do GRAC. Algumas das funções da equipe dessa Secretaria são, nas atividades de informação à mídia, difundir os boletins oficiais e atuar junto à Secretaria de Defesa Civil e à Comissão de Reconstrução.

\section{Reflexão: a mídia e os impactos}

Gerir riscos de desastres significa, entre tantos pontos, lidar com vários públicos e com a circulação de informações. Portanto, gerir um desastre passa necessariamente por gerir informações que circulam entre diferentes públicos. A comunicação é fundamental por si só, mas, num desastre, ganha importância ainda maior pela necessidade da sua existência para os muitos públicos envolvidos. Num momento de mundo, quando só em 2007 um total de 197 milhões de pessoas foram vítimas de desastres (ZUCCO; MAGALHÃES; MORETTI, 2010), a mídia, com seu alcance, torna-se um meio ideal para a disseminação de mensagens e conexão entre os diversos públicos (REIS, ZUCCO e DAROLT, 2013, p. 158). Um recorte no tema - manuais que orientam sobre a comunicação de riscos de desastres - conduziu a análise de quatro publicações e um livro, guiada por alguns questionamentos.

Há similaridades, mas também um distanciamento de enfoques nos materiais analisados. Enquanto o "Plano de Contingência - Inundações e Escorregamentos", de Blumenau (SC), não contemplou orientações para atuação da mídia durante desastres, o guia "Cobertura de Desastres e Crises", da ICFJ, na voz do jornalista e consultor Marcotte, destaca a importância fundamental da mídia no salvamento de vidas, por meio da transmissão de informações críticas sobre e para as regiões afetadas. Para Spence, Lachlan e 
Griffin (2007), a comunicação é tão importante em RRD que cumpre duas funções, tanto a informativa quanto a persuasiva.

Em se tratando das similaridades, em todos os manuais que englobaram o papel da mídia, foi constatado que os veículos de comunicação e o trabalho dos jornalistas podem fazer uma grande diferença na redução dos riscos de desastres (POTTER; RICCHIARDI, 2009; UNESCO, 2011; UNISDR, 2012; ZENATTI; SOUSA, 2010). Nesses guias, há o reforço de que a contribuição dos jornalistas deve centrar-se numa comunicação específica antes, durante e após um desastre. Apesar de pesquisa sobre as tendências de mídia e desastres nos últimos 20 anos (REIS; MATTEDI; BARRIOS; 2017) revelar a pouca atenção dada aos desastres antes que ocorram, é nesse momento que os comunicadores podem realizar um trabalho de cunho educativo, pois é o período em que as comunidades são mais receptivas às informações (UNESCO, 2011). É a fase em que os profissionais da comunicação podem enfocar os desastres passados, cobrir simulados e mesmo aproveitar a ocorrência de um desastre internacional para enfatizar os riscos de uma área (UNISDR, 2012). Podem ainda mostrar as causas e dimensões sociais de eventos anteriores, para que as comunidades compreendam o que as torna vulneráveis e quais ações podem ampliar suas capacidades para lidar com os desastres. Dessa forma, os profissionais favorecem uma mudança de comportamento e, também, contribuem com a prevenção dos desastres, fomentando uma cultura mais preventiva e menos reativa. O manual das Nações Unidas, por exemplo, na sua conclusão, destaca estes papéis da mídia (UNISDR, 2012). No entanto, o maior desafio está em encontrar espaços e incluir os temas relacionados à RRD nas páginas de notícias antes dos eventos (RADFORD; WISNER, 2012).

Em relação à atuação dos profissionais de comunicação durante um evento crítico, os manuais apontam que a amplitude da contribuição depende da cobertura realizada. Quanto mais profunda for na revelação das causas e das dimensões do evento (e não somente em fatos), na cobertura das histórias, na diversificação das fontes, nas perguntas, maior será a colaboração da mídia, inclusive para salvar vidas. No pós-evento, os guias ressaltam que a mídia contribui mais na medida que mantém o assunto vivo por mais tempo, concentrandose, por exemplo, em ações dos responsáveis pela gestão do desastre, nos recursos financeiros e políticas em RRD, bem como impactos econômicos, sociais e culturais do desastre (UNISDR, 2012). Existe a constatação, em quase todos os manuais, de que aos profissionais da comunicação cabe a missão de ir além da simples informação. Destacam a 
importância da mídia na conscientização, na educação e, principalmente, na prevenção, o que pode contribuir para reduzir as chances de uma ameaça natural se transformar num desastre (UNESCO, 2011; UNISDR, 2012; ZENATTI; SOUSA, 2010).

No emaranhado de públicos, dependendo do tipo de desastre e de sua abrangência, muitas vezes, uma das fontes principais é a assessoria de imprensa dos órgãos do governo. 0 livro "Comunicação em Desastres", do Governo do Estado de SC, reconhece a importância do trabalho da mídia e, da mesma forma, da assessoria de imprensa governamental, a qual, ressalta, deve organizar e priorizar dados e informações relevantes para acesso da imprensa (ZENATTI; SOUSA, 2010). Nesse sentido, a mídia depende desse fluxo de informações, e a fragilidade está na falta dele. Os desastres têm a capacidade de afetar o diálogo e a interação do poder público com a população (REIS; ZUCCO; DAROLT et al., 2013), e a mídia pode contribuir para isso. Portanto, a obra aponta um roteiro de como as assessorias de imprensa governamentais podem atuar em relação à mídia, reforçando a importância de estarem capacitadas para se relacionar com os veículos de comunicação. Destaca ainda a necessidade de o governo ter um plano para possíveis desastres em sua localidade, o qual contemple o trabalho da imprensa em todas as suas fases. Os profissionais da imprensa precisam ser envolvidos nos planos do governo; ter informações técnicas sobre o tema, para contribuir com a frente educacional e de conscientização (antes); possuir estrutura física e emocional (durante); e espaço na própria mídia para manter o tema vivo sob outras lentes (depois) (ZENATTI; SOUSA, 2010). Em outra direção, o manual, classificado como local, não trata do fluxo de informações entre a Prefeitura de Blumenau e a mídia. O guia aborda exclusivamente as atribuições da SECOM (Secretaria de Comunicação), à qual cabe difundir os boletins oficiais e atuar junto à Secretaria de Defesa Civil e à Comissão de Reconstrução, no que diz respeito às atividades de informação à mídia.

A preocupação com o bem-estar do jornalista está presente em praticamente todos os materiais, pois, na cobertura de um evento crítico, o profissional pode sofrer um grande impacto e, portanto, necessitar de orientações para manter o seu próprio conforto emocional (POTTER; RICCHIARDI, 2009; UNESCO, 2011; ZENATTI; SOUSA, 2010). O manual classificado como nacional menciona a segurança e o trauma de jornalistas como desafios na cobertura de desastres (ZENATTI; SOUSA, 2010). No entanto, o guia latino-americano e o material internacional "Cobertura de Desastres e Crises" se aprofundam no tema. Focam na saúde mental e na integridade física do jornalista, ressaltando que a vida está em primeiro 
lugar, e não a notícia. Fornecem orientações sobre como o profissional deve preparar-se para o que pode enfrentar e alertam para a possibilidade de absorção de uma enorme carga emocional. Ressaltam sobre a importância de o profissional ter consciência dos cuidados que deve ter em momentos de estresse e da necessidade das agências e veículos de comunicação fornecerem apoio moral aos jornalistas (POTTER; RICCHIARDI, 2009; UNESCO, 2011).

A terminologia sobre RRD é enfocada em três dos cinco manuais, o que revela a importância da padronização no uso de conceitos utilizados no gerenciamento de eventos adversos. Os termos técnicos da área incluem palavras como ameaça, desastre, risco, vulnerabilidade, prevenção, entre muitos outros, os quais podem facilitar a rápida comunicação entre os responsáveis pela gestão de desastres e simplificar a transmissão de informações à população, evitando confusões (UNESCO, 2011; UNISDR, 2012; ZENATTI; SOUSA, 2010).

\section{Considerações Finais}

A frequência e a intensidade de desastres no mundo todo, bem como seus impactos, são responsáveis pelo fortalecimento do tema na mídia e um espaço cada vez maior nas pesquisas acadêmicas. O conceito de desastres assenta-se sobre muitas perspectivas, dependendo da área que guia a investigação. O objetivo deste artigo foi o de analisar os manuais que orientam a comunicação de riscos de desastres e refletir sobre como a mídia pode contribuir para amenizar os esses impactos.

A pesquisa concentrou-se na identificação de manuais sobre a comunicação de riscos e desastres, na descrição do conteúdo e, por fim, na reflexão sobre como a mídia pode contribuir para amenizar esses impactos. Foram identificados nove manuais nos três idiomas pesquisados (português, espanhol e inglês). No entanto, foram escolhidos aqueles de organismos representativos, com ampla circulação, além da origem e abrangência. Dessa forma, contemplaram-se dois manuais internacionais, um latino-americano, um nacional e um local. Para este estudo, após o levantamento dos manuais, optou-se por analisar o conteúdo de todo o material tendo como guia três perguntas: Quais informações os manuais contêm? Quais são as orientações para a atuação da mídia em relação aos desastres? Como a mídia pode contribuir para amenizar os impactos de um desastre? 
Uma das principais contribuições desta pesquisa foi evidenciar que, em praticamente todos os manuais, o trabalho dos profissionais da mídia é valorizado e tem fundamental importância no tema RRD. Os conteúdos dos materiais destacam o papel da mídia no fortalecimento da conexão entre todos os públicos, na circulação das informações, na comunicação da dimensão dos riscos, na facilitação da compreensão do fato e, ainda, na possibilidade de influenciar a tomada de decisões das comunidades. Exceto em um deles, o que não aborda o trabalho dos comunicadores, nos demais guias, há uma preocupação em orientar a mídia para exercer o seu papel de maneira ampla, contribuindo socialmente com a gestão de riscos e desastres. Isto significa o reconhecimento da possibilidade de a mídia ir além da disseminação de informações, contribuindo com a conscientização, a educação e, principalmente, a prevenção dos desastres.

Porém este escopo mais amplo de atuação dos comunicadores demanda maior número de veículos e profissionais nas agências, ou mesmo especialistas no tema. Paralelamente, há uma realidade que aponta para bastidores da mídia cada vez com menos jornalistas, onde estão a fragilidade e as limitações dos materiais estudados, pois não há menção de como construir este mundo ideal, onde a mídia possa contribuir com seu papel social em desastres, tendo tão poucos profissionais.

Como oportunidade, sugere-se que pesquisas futuras examinem se existem comunicadores que têm conseguido manter o tema RRD vivo, mesmo em tempos de normalidade, e de que maneira e por quais canais esses profissionais estão conseguindo espaço. Além disso, pode abrir-se uma nova linha de investigação para analisar também se os órgãos governamentais têm promovido debates sobre o tema - e mesmo treinamento para a mídia -, aos quais recorrem a cada evento crítico.

\section{Referências}

AVILA, M.R.; MATTEDI, M. A. As dimensões políticas da produção de desastres: o caso do território do Vale do Itajaí/SC. Seminário Internacional sobre Desenvolvimento Regional. UNISC, 2015. Disponível em: http://online.unisc.br/acadnet/anais/index. php/sidr/article/view/13308. Acesso em: 20 fev. 2017.

BARDIN, L. Análise de conteúdo. 2. ed. Lisboa: Edições 70, 2010. 
BARRIOS, M. M.; ARROYAVE CABRERA. J.; VEGA-ESTARITA, L. El cambio de paradigma en la cobertura informativa de la gestión de riesgo de desastres. Chasqui. Revista Latinoamericana de Comunicación, [S.I.], n. 136, p. 129 - 144, dic. 2017. ISSN 1390-924X.

BLUMENAU. Plano de Contingência - Inundações e Escorregamentos, Defesa Civil, Secretaria Municipal de Defesa do Cidadão, Prefeitura Municipal de Blumenau, 2016.

BRUNS, A; LIANG, Y.E. Tools and methods for capturing Twitter data during natural disasters. Peer-Reviewed Journal on the Internet. v. 17, n. 4, 2012. Disponível em:

http.journals.uic.edu/ojs/index.php/fm/article/view/3937/3193/ Acesso: 20 mar. 2017.

CROWE, A. The application of Social Media Systems for Modern Emergency Management. CRC Press. Taylor \& Francis Group, 2012.

HANS, A.; MOHANTY, R. Disasters, disability and technology. Development. v. 49, n. 4, p.119-122, 2006.

HUANG, J.; LIU, Y.; MA, L. Assessment of regional vulnerability to natural hazards in China using a DEA Model. International Journal of Disaster Risk; 2 (2), p. 41-48, 2011.

MATTEDI, M. A.; BUTZKE, I. C. A relação entre o social e o natural nas abordagens de hazards e de desastres. Ambiente \& Sociedade, 9, 10-21, 2001. Disponível em: http://www. scielo.br/pdf/asoc/n9/16877.pdf. Acesso em: 15 jan. 2017.

NAÇÕES UNIDAS (UNISDR). Estratégia Internacional para Redução de Desastres: o desastre sob o enfoque de novas lentes: para cada efeito, uma causa/Brigitte Leoni, Tim Radford, Mark Schulman; tradução Sarah Marcela Chinchilla Cartagena. São Paulo: CARE Brasil, 2012. Tradução de: Disaster through a different lens: behind every effect, there is a cause.

NEUENDORF, K. A. The Content Analysis Guidebook. Thousand Oak, CA: Sage, 2002.

POTTER, D.; RICCHIARDI, S. Disaster and Crisis Coverage. International Center for Journalists, 2009.

RADFORD, T.; WISNER, B. Media, Communication and Disaster. In: WISNER, B.; GAILARD, J.C.; KELMAN I. (eds.) The Roudledge Handbook of Hazards and Disaster Risk Reduction. London: Routledge, 2012. p. 761- 771

REIS, C; MATTEDI, M.A.; REIMONDO BARRIOS, Y. Mídia e desastres: panorama da produção científica internacional de 1996 a 2016. Intercom: Revista Brasileira de Ciências da Comunicação, v. 40, n. 2, p. 77-92, 2017.

; ZUCCO, F.; DAROLT. E. Gabinete de Crise versus mídia: implicações para o diálogo com a comunidade. Intercom (São Paulo, Impresso), v. 36, p. 155-173, 2013.

SPENCE, P.R.; LACHLAN, K.A.; GRIFFIN, D.R. Crisis communication, race, and natural disasters. Journal of Black Studies, v. 37, p. 539-562, 2007. 
UNESCO. Manual de gestión del desastre para comunicadores sociales. Lima, 2011.

ZENATTI, A. P. A; SOUSA, S.Y.U. Comunicação em Desastres: a atuação da imprensa e o papel da assessoria governamental. Florianópolis: CEPED, 2010. Disponível em: http://www.ceped.ufsc.br/sites/default/files/ projetos/guia_para_cobertura_jornalistica_em_rrd.pdf.> Acesso em: 7 dez. 2016.

ZUCCO, F. D.; MAGALHÃES, M. R. A.; MORETTI, S. L. A. Gestão de riscos e desastres naturais no turismo: um estudo do município de Blumenau/SC. Turismo em Análise. Blumenau, v. 21, n. 3, dezembro 2010. Disponível em: http://www.spell.org.br/documentos/download/6136. Acesso em: 13 fev. 2017. 